\title{
SATISFACTION WITH DENTAL AND MEDICAL EDUCATION QUALITY AMONG FOREIGN STUDENTS CONSIDERING NON-NATIVE ENGLISH- SPEAKING ORIGIN OF THE TEACHERS
}

\begin{abstract}
Objectives: To evaluate satisfaction with dental and medical education quality among foreign students considering non-native Englishspeaking origin of the teachers.
\end{abstract}

Materials and Methods: This research was conducted in the form of a questionnaire survey among foreign students of Dental Faculty and Medical Faculty during 2019-2020. The questionnaire was presented in the format of Google-form, published in faculties' social media group as well as was sent to the e-mail of each student registered via Moodle system. The survey was held considering the anonymity of each respondent and personal willingness of each student to take part in the research. One hundred and sixty-seven students took part in the survey, among which only 82 answered all the questions.

Results: 60 (73.2\%) respondents rated their satisfaction with the quality of provided educational process as excellent, while $5(6.1 \%)$ and 17 $(20.7 \%)$ as satisfactory and good, respectively. Such factors as teacher's/lecturer's knowledge of the subject $(\mathrm{r}=0.72)$, teacher's/lecturer's knowledge of English ( $\mathrm{r}=0.60)$, personal motivation $(r=0.75)$, and educational organization considering the aspect of language adaptation $(\mathrm{r}=0.65)$ were found to be statistically related to the quality of obtained dental and medical education, subjectively evaluated by the foreign students.

Conclusions: Considering limitations of the performed study, it could be resumed that foreign students are generally highly satisfied with provided level of dental and medical education, even though such was carried out by the lecturers for whom English isn't the native language. Structured interactive sessions, direct-feedback lectures, and additional use of video-podcast are not only preferable among students, but also provide sufficient opportunities for educational process improvement, especially in the settings when both student and teacher are non-native English speakers, and when stationary education is limited due to the COVID-19 pandemic situation.

Keywords: Foreign medical graduates, education, dental, medical, communication barriers.
iD * Myroslav Goncharuk-Khomyn ${ }^{1}$

iD Allessandro Leite Cavalcanti ${ }^{2}$

D Olesia Stoika ${ }^{3}$

D Marharyta Hliudzyk-Shemota ${ }^{4}$

Yulia Deviatko ${ }^{5}$

Alina Boykiv 6

ORCID IDs of the authors:

M.G.K. 0000-0002-7482-3881

A.L.C. $\quad 0000-0003-3572-3332$

O.S. 0000-0002-7695-6100

M.H.S. $\quad 0000-0001-7937-6489$

Y.D. $\quad 0000-0002-6059-5873$

A.B. $\quad 0000-0001-9370-1348$

\footnotetext{
${ }^{1}$ Director of Scientific and Research Center of Forensic Odontology, Department of Public Health and Humanitarian Disciplines, Uzhhorod National University, Uzhhorod, Ukraine.

${ }^{2}$ Department of Dentistry, State University of Paraíba, Campina Grande, Brazil.

${ }^{3}$ Department of Foreign Languages, Uzhhorod National University, Uzhhorod, Ukraine.

${ }^{4}$ Department of Basic Medical Sciences, Uzhhorod National University, Uzhhorod, Ukraine.

${ }^{5}$ Department of Applied Linguistics, Odesa National University, Odesa, Ukraine.

${ }^{6}$ Department of Orthopedic Dentistry, I. Horbachevsky Ternopil National Medical University, Ternopil, Ukraine.
}

Received : 26.07 .2020 Accepted : $: 28.09 .2020$ 


\section{INTRODUCTION}

Medical and dental education of foreign students represents a complex system of students-teachers interactions, characterized with formation of further academical and professional networks worldwide. ${ }^{1-5}$ Based on the numbers of graduated specialists and those who had nostrificate their original diplomas in other countries, process of dental and medical education of foreign students seems to progress and improve gradually over past decade, and it could be defined as internationally successful process. Considering such tendency, the convergence of European dental educational models have been described previously. ${ }^{6-9}$ Latter included usage of the same educational protocols with translations into different languages at universities and further discussion on aspects related to the general and subject-specific competences, ECTS-mode as accumulation mechanism and educational process quality assessment. ${ }^{9}$

As reported by the State Enterprise "Ukrainian State Center for International Education", number of foreign students in Ukraine reached 80,470 in 2019 compared to 53,664 in 2011 , while $87.85 \%$ of them are seeking bachelor's and master's degree education. ${ }^{10}$ Based on the previous study, selection of an international institution for degree education was associated with the influence of such factors as academic quality and reputation, internationalization, amount of tuition fee, student-oriented educational process and availability of scholarships. ${ }^{11}$ Language factor also remains one of the most important to choose among universities abroad, while English is considered as an international language for providing an educational process among foreign students. Foreign languages courses within medical curriculum tend to help foreign students integrate into social network not only among academic environment, but also beyond it. ${ }^{11}$

The number of foreign students tends to increase in Ukraine and that is related to such factors as a progression of academic mobility possibilities, seeking for a degree education at a foreign country, development of exchange educational programs, and optimization of student enrollment process for university education worldwide. Even though most of the academic staff not only in Ukraine but worldwide, has high English language fluency skills, it is still important to notice that educational process for foreign dental and medical students in many cases is provided by the teachers of non-native English-speaking origin.

Considering all above-mentioned information, it is reasonable to resume that the research of specific aspects during dental and medical education of foreign students proceeds relevant and actual, while working out in detail of such could improve overall quality of provided academic activity.

\section{OBJECTIVE}

To evaluate satisfaction with dental and medical education quality among foreign students considering non-native English-speaking origin of the teachers.

\section{MATERIALS AND METHODS}

The research was provided in the form of a questionnaire survey among foreign students of Dental Faculty and Medical Faculty \#2 at Uzhhorod National University (Ukraine) during 2019-2020 years. The questionnaire was presented in the format of Google-form, published in faculties social media group, and/or sent to the email of each student registered via Moodle system. Students without Moodle-account couldn't take part in the survey, which was limited by access algorithm. Before getting access to the questionnaire, student should mention the year of study in corresponding text box without indication his/her name or other personal information. Using of Google-form as a questionnaire optimize the possibilities for further data collection and analysis of obtained results.

The questionnaire used for grading satisfaction with medical and dental education was modified compared to the analogical versions provided in previous publications and was adapted considering the aspects of students and teachers language origin impact. ${ }^{12,13}$ The questionnaire consisted of 11 questions, representing three different domains. The first domain included questions from 1 to 5 , and was aimed at subjective evaluation of overall satisfaction with provided 
education quality, and teachers'/students' knowledge of English. Respondents could choose one of the 5 proposed possible answers, represented in percentage meanings from $0 \%$ to $100 \%$ with each interval of $20 \%$ interpreted in following manner: 0-20\% - poor, $21-40 \%$ - weak, $41-60 \%$ - satisfactory, $61-80 \%$ - good, $81-100 \%$ excellent. The second domain presented by questions 6-10 was related to the subjective evaluation of possible connections between the quality of provided education and related factors, considering the impact of English fluency. In this domain, respondents also could choose one of the 5 proposed possible answers, represented in the meanings of absolute values from 1 to 5 , which was interpreted in the following fashion: $1-$ no connection, 2 - weak connection, 3 - moderate connection, 4 - good connection, 5 - strong connection. The third and last domain was presented only by question number 11 aimed at the verification of the most effective and motivational type of lesson considering its' possible subjective impact on the knowledge of English language. Respondents could choose one of the proposed 5 possible answers or propose their own one. Five options for answering on the question number 11 included the following: 1) lecture with no student's interaction; 2) direct-feedback lectures; 3) seminar; 4) interactive sessions with a small group of students; 5) distance (remote) learning using podcasts and provided material for preparation.

The above stated 11 questions within questionnaire were formulated as follows:

1. What is your overall satisfaction with the quality of obtained education?

2. What is your overall satisfaction with organization of educational process, considering aspects of language adaptation?

3. How do you evaluate the overall English fluency among teachers/lecturers you have worked with?

4. Grade your own knowledge of English before you attempt the university.

5. Grade your own knowledge of English after finishing the previous study year at university.
6. Rate the connection between teacher's/lecturer's knowledge of subject and quality of provided education.

7. Rate the connection between teacher's/lecturer's knowledge of English and quality of provided education.

8. Rate the connection between your own knowledge of English and quality of provided education.

9. Rate the connection between your own impact and motivation on the outcome of provided education.

10. Rate the connection between length of studying at university and improvement of your knowledge including improvement of your English language.

11.Identify the most motivational and effective type of lesson considering their positive influence on knowledge of English.

Survey was held considering the anonymity of each respondent and personal willingness of each student to take part in the research. One hundred sixty-seven students took part in the survey, among which only 82 answered all the questions. Due to the need for correct interpretation of all obtained results, answer's forms with incomplete information were not considered for further analysis.

The study was approved by the Ethic Committee of Medical Faculty \#2 (Uzhhorod National University) within Group of studies aimed at educational process optimization and designated with the number of № 22092019 (22/09/2019).

All data obtained via Google-form (questionnaire) was transferred to the Microsoft Excel 2019 software (Microsoft Office 2019, Microsoft), where further data structuring and tabulation were performed. Descriptive statistics methods were used for obtained data summarization (distribution of obtained results, mean values, absolute levels of respondents' answers). Correlation between factors related to knowledge of English and quality of obtained education was evaluated using correlation function (Pearson's $r$ ) with $\mathrm{p}<0.05$ considered as adequate level of probability. ${ }^{14}$ 


\section{RESULTS}

Among 82 fully completed forms, 18 (21.9\%) were provided by $2^{\text {nd }}$ year students, $39(47.6 \%)-$ by $3^{\text {rd }}$ year students, and $25(30.5 \%)-$ by $4^{\text {th }}$ years students. Even though some freshmen, seniors $\left(5^{\text {th }}\right.$ year) and final year $\left(6^{\text {th }}\right.$ year) students submitted answer forms, but none of them have completed it to the full extent, without missing or ignoring some of the provided questions. The most frequently missed question (57.6\%) was one from the third domain, considering type of lesson that could have the greatest impact on knowledge of English language. Nevertheless, obtained distribution of the answers among representatives of different years of studying was sufficient to provide further analysis of the data.

Considering obtained answers on first domain's questions (1-5), it was found that 60 (73.2\%) respondents rated their satisfaction with the quality of provided educational process as excellent, while $5(6.1 \%)$ and $17(20.7 \%)$ as satisfactory and good, respectively. Similar distribution was noted regarding answers on overall satisfaction with obtained educational organization, considering aspects of language, with 61 (74.4\%), $18(21.9 \%)$ and $3(3.7 \%)$ respondents demonstrating excellent, good and satisfactory levels, respectively. Students evaluated the overall level of teacher's/lecturer's knowledge of English as good (by 37.8\% respondents) and excellent (by $53.7 \%$ respondents). On the other hand, 16 students (19.5\%) graded their level of English as weak before entering the university, while 31 (37.8\%) as satisfactory, $23(28.1 \%)$ - as good, and 12 $(14.6 \%)$ - as excellent. Provided analyses also revealed that students subjectively noted the improvement of their knowledge of English during studying dentistry and medicine in the university: $33(40.2 \%)$ respondents graded their English knowledge as excellent, while $37(45.1 \%)$ as good after finishing previous academic year.

Based on the answers received within the second domain's questions, it was found that all respondents linked the quality of provided dental and medical education with the teacher's/lecturer's knowledge of the subject, while only $50 \%$ of them indicated the correlation between quality of provided education and teacher's/lecturer's knowledge of English. It was interesting that 16 students (19.5\%) didn't recognize any connection or identify just weak matching between educational outcome and their own knowledge of English. On the other hand, only 14 students $(17.1 \%)$ mentioned that there is a strong connection between the above-mentioned parameters. Still, 29 respondents (35.4\%) agreed that their personal impact and motivation had a strong influence on the outcome of provided dental and medical education, while 26 (31.7\%) and 27 (32.9\%) evaluated such connection as moderate and good, respectively. 45 (54.9\%) of surveyed students also strongly linked together the improvement of English and the duration of their study at university.

Among all proposed options for answering within the third domain's question, 37 (45.1\%) of the dental and medical students preferred interactive sessions with a small group of participants as the most efficient lessons considering their positive influence on knowledge of English language, while 23 (28.1\%) have chosen "direct-feedback lecture" answer for the same question. Lectures with no student's interaction, seminars and distance (remote) learning using podcasts and provided material for preparation were chosen as those accompanying learning of English only by 7 (8.5\%), 10 (12.2\%), and 5 (6.1\%) respondents, respectively.

Due to the all above obtained data and provided statistical analysis such factors as teacher's/lecturer's knowledge of the subject $(\mathrm{r}=0.72)$, teacher's/lecturer's knowledge of English $(\mathrm{r}=0.60)$, personal motivation $(\mathrm{r}=0.75)$, and educational organization, considering aspect of language adaptation $(r=0.65)$ were found to be statistically related to the quality of obtained dental and medical education, subjectively evaluated by the foreign students; student's primary English knowledge and duration of studying demonstrated statistically lower levels of correlation. On the other hand, the outcome level of foreign students' knowledge of English was influenced in relatively the same manner by all of the above-mentioned factors, except teacher's/lecturer's knowledge of 
the subject. Also, duration of studying dental and medical subjects at university demonstrated a positive impact on resulted knowledge of English among foreign students ( $\mathrm{r}=0.59)$ (Table 1).

Table 1. Correspondence between studied parameters, obtained quality of education and outcome knowledge of English

\begin{tabular}{|c|c|c|c|c|}
\hline \multirow[t]{2}{*}{ Factors } & \multicolumn{2}{|c|}{$\begin{array}{l}\text { Quality of } \\
\text { education }\end{array}$} & \multicolumn{2}{|c|}{$\begin{array}{c}\text { Outcome knowledge of } \\
\text { English }\end{array}$} \\
\hline & $\mathrm{r}$ & $\mathrm{p}$ & $\mathrm{r}$ & $\mathrm{p}$ \\
\hline Teacher's/Lecturer's knowledge of the subject & 0.72 & $\mathrm{p}<0.05$ & 0.21 & $\mathrm{p}<0.05$ \\
\hline Teacher's/Lecturer's knowledge of English & 0.60 & $\mathrm{p}<0.05$ & 0.52 & $\mathrm{p}<0.05$ \\
\hline Student's knowledge of English at baseline & 0.36 & $\mathrm{p}<0.05$ & 0.61 & $\mathrm{p}<0.05$ \\
\hline $\begin{array}{l}\text { Educational organization considering the aspect of language } \\
\text { adaptation }\end{array}$ & 0.65 & $\mathrm{p}<0.05$ & 0.76 & $\mathrm{p}<0.05$ \\
\hline Personal motivation and impact & 0.75 & $\mathrm{p}<0.05$ & 0.59 & $\mathrm{p}<0.05$ \\
\hline Duration of education & 0.41 & $\mathrm{p}<0.05$ & 0.59 & $\mathrm{p}<0.05$ \\
\hline
\end{tabular}

\section{DISCUSSION}

Dental and medical education aimed at providing and developing competent knowledge, skills and abilities among students and postgraduates, thus guarantying ongoing improvements within the health care academical and professional community. ${ }^{1-3,10}$ Educational process itself represents translational phase for a future specialist, while being more advanced lifeexperience for students attending universities abroad in comparison with those obtaining degree at resident country. ${ }^{2,45}$ Foreign students who are not originally English-speaking faced challenges mastering not just English itself, but medical and dental English terminology during corresponding curriculums. In some countries, dental and medical education provided by academic staff for whom English is also not a native language, thus forming situations in which non-native English speakers teaching non-native English-speaking students. An interesting trend have been noted during the analyses of foreign students' enrollment in Ukrainian education system: the number of students from post-soviet countries demonstrated decreasing pattern from $29.47 \%$ in $2017-2018$ to $21.52 \%$ in $2019-2020$, while $22.90 \%$ and $10.23 \%$ of all students in 2019-2020 came from India and Morocco, respectively. ${ }^{10}$

Such a decreasing tendency of students' enrollment from post-soviet countries has also impacted the teaching process, considering the language aspect: English is becoming more requisite as teaching language considering the origin of foreign students.
Due to the results of our study, aimed at the assessment of subjective satisfaction with provided education among foreign students, it was found that the latter is predominantly dependent on such factors, as teacher's/lecturer's knowledge of the subject, teacher's/lecturer's knowledge of English, educational organization, considering the aspect of language adaptation, and personal motivation and impact. Among these factors, the influence of English knowledge among teachers/lecturers could not be categorized as being the most substantial, while personal motivation and teacher's/lecturer's knowledge of the subject demonstrated comparatively greater correlation with registered high satisfaction level with obtained education quality. Nevertheless, students evaluate the teacher's/lecturer's knowledge of English as good in $37.80 \%$ responses, and as excellent in $53.66 \%$ responses. Even though for the majority of academic staff providing dental and medical education at Ukrainian university English is not a native language, but such pattern of distribution could be related to the fact that all teachers providing educational process for the foreign students were previously certified with B2 (high intermediate) or C (advanced) levels of English by one of various grading tests (IELTS, FCE, TOEFL, APTIS, etc.).

Previous studies demonstrated that near $75 \%$ of analyzed US hospitals provided medical care for patients who are not native English speakers, while only $18 \%$ of surveyed medical facilities validated the level of foreign language proficiency among stuff. ${ }^{15-19}$ Based on that, authors resumed that 
assessment of foreign language skills should be categorized as a mandatory measure within medical educational system, while improvement of such should be provided by specifically design of language training courses. ${ }^{19}$ Such English language mastering by individual or group patterns together with English language curriculum classes could improve the overall quality of dental and medical education among foreign students. Moreover, learning of foreign language in general supports dental competencies development related to the dental care of patients with different sorts of disabilities. Such educational approach could be realized through the specially developed elective courses. ${ }^{20}$

Mitchell C. et $a l_{.}{ }^{21}$ noted the need for supportive English-speaking opportunities for the optimization of international nursing students' education. Such approach could reduce the risk of students being accused in deficiency of language or even in deficiency of clinical proficiency. ${ }^{21}$ Mykhailenko L. categorized "foreign language professional competence" as an important part of general professional competence within condition of postgraduate medical education system. ${ }^{22}$ Addition of new subject such as "Medical/Dental English for foreign students" within medical/dental core course curriculum supports an idea of future specialists' integration into professional field with relevant knowledge of active practical and theoretical trends. In the same manner, not only increasing the academic hours for English teaching but also modification of such in the way of its adaptation to clinical needs will help to enhance the general quality of medical and dental education.

The teacher guidance remains one of the factors associated with the success of education, especially in the settings of foreign students' educational process. Even though interaction and student inter-guidance are also the methods of teaching modes within some classes, but the dominant role of mentoring should be held by teacher/lecturer. Previously, it was established that student-made educational podcasts did not pronounce any improvement in foreign language vocabulary teaching, while teacher-produced ones support the increase of foreign language skills. ${ }^{23}$
Results of systematic review demonstrated that none of the analyzed teaching methods demonstrated significantly greater effectiveness compared to others, but still video-based ones characterized with greater positive impact on average knowledge scores. ${ }^{24}$ Usage of virtual classrooms supported better educational outcomes among Chinese and foreign students in China in three medical schools. ${ }^{25}$ Such outcome is associated with great relevant importance considering the need for distant education implementation due to the COVID-19 pandemic conditions.

However, due to the results obtained considering teaching and learning modes, it was found that such methodologies as interactive lectures, case-based lectures and problem-based learning approaches demonstrated statistically significant positive impact on reaching educational objectives, while structured interactive session were characterized by greater ability to solve complicated aspects. ${ }^{26}$ Considering such outcomes, it is reasonable to recommend the usage of structured interactive sessions for English learning during dental and medical education, since concept of such is also more adapted for clinical orientation of language skills among future medical specialists. On the other hand, team-based learning was associated with greater examination scores, higher levels of learning attitude and learning skills compared to lecture-based learning due to the results of provided meta-analysis among medical educational environment in China. ${ }^{26}$ Team-based learning also provides possibilities of medical English language skills improvement in terms of student and teacher both-way interaction, while just classical lecturing itself restricts such options.

In our study, students have chosen interactive sessions with a small group of participants and direct-feedback lectures as the most efficient types of lessons considering their positive influence on knowledge of English language during dental and medical studying. Despite all the analyzed modifications of dental and medical educational models, the principle of blended mode of learning, consisting of various teaching methodologies, seems to provide the most effective results on 
overall educational quality regardless of students' and lecturers' language origin. ${ }^{28,29}$

Analysis of international medical students' expectations provided within the focus group, revealed that social exclusion because of foreign language knowledge deficiency is one of the most reported students' worries, which could be compensated by corresponding language training courses. ${ }^{2}$ Results obtained in nationwide survey have shown that even though medical education for foreign students were provided via English or French in general, but $88.5 \%$ were confident in providing medical history in their native language. ${ }^{30}$ In previous study, foreign language was categorized as an obstacle for medical students during the $1^{\text {st }}$ year, but after that, the language barrier was not considered as a problem. ${ }^{31}$ In our study, we have found out that educational process organization, considering the aspect of language adaptation, seems to be an influential factor both on students' satisfaction regarding the quality of education, and on the outcome of English knowledge among dental and medical students. Moreover, it was noted that the duration of study has a positive influence on outcome of English knowledge among dental and medical foreign students. Educational process organization, considering the aspect of language adaptation includes additional pre-entry English courses, activities involving students' interaction, teachers' support while dealing not only with educational, but also with usual life situations, and full language support provided by translators or senior students. Such approach is organized at the faculty level and could be effectively implemented as an integrated educational strategy.

The problem of insufficient English language skills among foreign students is also critical during classical lecturing since the absence of response restricts the chances of complete and adequate knowledge sharing. ${ }^{32}$ On the other hand, students themselves preferred active learning methodologies, which included conductive learning function, motivational aspects and repetitive feedback ${ }^{32}$, which was also registered in our study.
In research provided by Hanna, foreign students demonstrated a higher level of satisfaction while studying medical behavior disciplines compared to their German colleagues. ${ }^{12}$ Such results were associated with a component of generally deeper experience of foreign students studying abroad considering their "broader life situation". ${ }^{12}$ Answers received from foreign students enrolled in our survey also demonstrated the high level of satisfaction with obtained education quality at the excellent level among $73.17 \%$ of respondents.

Understanding of foreign students' present and further needs considering English language impact helps to organize highly qualitative system of language training activities oriented toward real situation conditions. ${ }^{34}$ As it has been shown in previous research, dental and medical students mostly use the next major strategies for vocabulary learning: guessing, selective attention, study preference, dictionary use and memory. ${ }^{13}$ Also, supportive English lessons could promote deeper cross-disciplinary integration, as it has been shown previously with other subjects. ${ }^{35}$ Another perspective of medical sciences education improvement considering English language communication skills represented by exchange programs, forming the chances for teachers and for students to be involved in the educational process within a totally English-speaking environment.

Despite the high number of foreign students not only in Ukraine, but worldwide, it could be resumed that educational system while still developing going through total globalization and integration processes. ${ }^{1-3,36}$ New challenges occur considering not only academically associated changes, but also influence of "out of educational field" factors, such as COVID-19 pandemic and limited territorial migrations related to sanitary restrictions. ${ }^{37}$

This study characterized with a few limitations, which are following: 1) provided questionnaire itself was composed in English, and there were no alternatives questionnaires presented in respondents' native languages; 2) students background was not considered as a potential factor of influence on the subjective assessment of 
education satisfaction; 3) evaluation of satisfaction with education quality was provided considering students' general impression among all studied subjects, while some of them could be related to greater intellectual endeavors and more complicated vocabulary content, and other could be characterized as less complex. All the abovementioned limitations associated with pilot design of the study. Even though used questionnaire was composed just in English version, but it was represented in the simplest way possible with minimal chances of some aspects misinterpretations. Students' background is a valuable factor of influence during research of satisfaction with an educational program, but such will be differentiated during further in-depth analysis, and will be considered as a perspective of future research. The same way differentiation of various subjects' learning aspects on overall satisfaction with educational process will be studied in the future, but for such research the new groundbase should be prepared considering the need in pre-analysis of objectified academic load difference between various kinds of disciplines.

\section{CONCLUSIONS}

Considering the limitations of conducted study, it could be resumed that foreign students are generally highly satisfied with provided level of dental and medical education at Ukrainian university, even though such was carried out by the lecturers for whom English isn't a native language. Such outcome could be argumented by the fact that most of the lecturers certified with English knowledge at the levels of B2 (high intermediate) or C (advanced). Moreover, students' satisfaction with the quality of provided education was statistically associated with educational organization, considering the aspect of language adaptation and personal motivation. The same factors relatively similar have influenced on the outcome knowledge of English among foreign students who attended dental and medical courses at Ukrainian university. Structured interactive sessions, direct-feedback lectures and additional use of video-podcast are not only preferable among foreign dental and medical students, but also provide sufficient opportunities for educational process improvement, especially due to the conditions, when both student and teacher are nonnative English speakers, and when stationary education is limited due to the COVID-19 pandemic situation.

\section{ACKNOWLEDGEMENTS}

Presented study was not supported by a grant or any other kind of funding.

\section{CONFLICTS OF INTEREST STATEMENT}

Authors declare no conflicts of interest

\section{REFERENCES}

1. Gilavand A. The comparison of Iranian and foreign students' motivations to choose dentistry field of study. Int J Pediatr 2016;4(6):1993-2010.

2. Huhn D, Huber J, Ippen FM, Eckart W, Junne F, Zipfel S, Herzog W, Nikendei C. International medical students' expectations and worries at the beginning of their medical education: a qualitative focus group study. BMC Med Educ 2016;16(1):33.

3. Ohwo V. Integrating Global Health into the Medical Curriculum: Experience of Foreign Students in Ukraine. Int J Med Stud 2017;5(2):84-86.

4. Homonyuk O, Avramenko N. Foreign experience in mastering medical professional terminology by foreign students at medical universities. Comp Prof Ped 2017;7(4):32-38.

5. Machul M, Bieniak M, Chałdaś-Majdańska J, Bąk J, Chrzan-Rodak A, Mazurek P, Pawłowski P, MakuchKuśmierz D, Obuchowska A, Bartoszek A, Karska K. Lifestyle Practices, Satisfaction with Life and the Level of Perceived Stress of Polish and Foreign Medical Students Studying in Poland. Int J Environ Res Public Health 2020;17(12):4445.

6. Iacopino AM. The influence of "new science" on dental education: current concepts, trends, and models for the future. J Dent Educ 2007;71(4):450-462.

7. Ariana A, Amin M, Pakneshan S, Dolan-Evans E, Lam AK. Integration of traditional and e-learning methods to improve learning outcomes for dental students in histopathology. J Dent Educ 2016;80(9):1140-1148.

8. Snyman WD, Kroon J. Vertical and horizontal integration of knowledge and skills-a working model. Eur J Dent Educ 2005;9(1):26-31.

9. Plasschaert AJ, McLoughlin J, Keogh J. European Convergence in Dental Education, the DentEd III project. OHDMBSC 2007;6(3):18-31. 
10. Ministry of Education and Science of Ukraine State Enterprise "Ukrainian State Center for International Education". Available at: https://studyinukraine.gov.ua/en/ 11. Roga R, Lapiņa I, Müürsepp P. Internationalization of higher education: Analysis of factors influencing foreign students' choice of higher education institution. Procedia Soc Behav Sci 2015;213:925-930.

12. Hanna M. Foreign students in Germany: a comparative report of satisfaction with medical behavioral sciences education. Swiss Med Wkly 2005;135(39-40):594-598

13. Hashemia $Z$, Hadavia $M$. Investigation of Vocabulary Learning Strategies Among EFL Iranian Medical Sciences Students. Procedia Soc Behav Sci 2015;192:629-637.

14. Mukaka MM. A guide to appropriate use of correlation coefficient in medical research. Malawi Med J 2012;24(3):69-71.

15. Regenstein M, Andres E, Wynia MK. Appropriate use of non-English-language skills in clinical care. JAMA 2013;309(2):145-146.

16. Huang J, Jones KC, Regenstein M, Ramos C. Talking with patients: How hospitals use bilingual clinicians and staff to care for patients with language needs. Health Pol Manag 2009;9:1-4.

17. Regenstein M, Huang J, West C, Trott J, Mead H, Andres E. Improving the quality of language services delivery: findings from a hospital quality improvement initiative. J Healthc Qual 2012;34(2):53-63.

18. Regenstein M, Andres E, Nelson D, David S, Lopert R, Katz R. Medication information for patients with limited English proficiency: lessons from the European Union. J Law Med Ethics 2012;40(4):1025-1033.

19. Tucker JD, Chen AH, Glass RI. Foreign language assessment and training in US medical education is a must. Acad Med 2012;87(3):257.

20. Campos VA, Cartes-Velásquez R. Developing competencies for the dental care of people with sensory disabilities: A pilot inclusive approach. Cumhur Dent J 2020;23(2):107-115.

21. Mitchell C, Del Fabbro L, Shaw J. The acculturation, language and learning experiences of international nursing students: Implications for nursing education. Nurse Educ Today 2017;56:16-22.

22. Mykhailenko L. The development of the physicians's foreign language professional competence in the system of postgraduate education. Prof Educ Meth Theo Tech 2017;6:250-266.
23. Çölkesen D, Bedir G. The use of student-produced educational podcasts in foreign language vocabulary teaching. Int J Res Educ Soc Sci 2016;1(3):2415-2528. 24. Gopinath V, Nallaswamy D. A systematic review on the most effective method of teaching dentistry to dental students compared to video based learning. Am J Educ Res 2017;5(1):63-68.

25. Shi C, Wang L, Li X, Chai S, Niu W, Kong Y, Zhou W, Yin W. Virtual classroom helps medical education for both Chinese and foreign students. Eur J Dent Educ 2015;19(4):217-221.

26. Rehan R, Ahmed K, Khan H, Rehman R. A way forward for teaching and learning of Physiology: Students' perception of the effectiveness of teaching methodologies. PaK J Med Sci 2016;32(6):1468-1473.

27. Chen M, Ni C, Hu Y, Wang M, Liu L, Ji X, Chu H, Wu W, Lu C, Wang S, Wang S. Meta-analysis on the effectiveness of team-based learning on medical education in China. BMC Med Educ 2018;18(1):77.

28. Karamizadeh Z, Zarifsanayei N, Faghihi AA, Mohammadi H, Habibi M. The study of effectiveness of blended learning approach for medical training courses. Iran Red Crescent Med J 2012;14(1):41-44.

29. Maza EM, Lozano MT, Alarcón AC, Zuluaga LM, Fadul MG. Blended learning supported by digital technology and competency-based medical education: a case study of the social medicine course at the Universidad de los Andes, Colombia. Int J Educ Technol H 2016;13(1):1-3.

30. Abi Raad V, Raad K, Daaboul Y, Korjian S, Asmar $\mathrm{N}$, Jammal M, Bahous SA. Medical education in a foreign language and history-taking in the native language in Lebanon-a nationwide survey. BMC Med Educ 2016;16(1):298.

31. Sabbour SM, Dewedar SA, Kandil SK. Language barriers in medical education and attitudes towards Arabization of medicine: student and staff perspectives. East Mediterr Health J 2012;16(12):1263-1271.

32. Yoltukhivskyy M, Nikolaenko O, Omelrenko O, Bogomaz O, Gusakova I. Peculiarities of teaching foreign students at the Department of the normal physiology of Vinnytsia National Pirogov'Memorial Medical University. Europ Hum Stud 2019;17(1):105117.

33. Rodis OM, Locsin RC. The implementation of the Japanese Dental English core curriculum: active learning based on peer-teaching and learning activities. BMC Med Educ 2019;19(1):256. 
34. Stavreva-Dorostolska S, Peneva K, SkochevaShopova E. Developing specialized linguistic competence in foreign students studying medicine. JAHR 2013;4(1):583-599.

35. Biduchak A, Mandryk-Melnychuk M. The specifics of teaching the history of medicine to foreign students. Cur Iss Soc Sci 2019(2):105-109.
36. Scalese RJ, Obeso VT, Issenberg SB. Simulation technology for skills training and competency assessment in medical education. J Gen Intern Med 2008;23(1):46-49.

37.Peres KG, Reher P, de Castro RD, Vieira AR. COVID-19-Related Challenges in Dental Education: Experiences From Brazil, the USA, and Australia. Pesqui Bras Odontopediatria Clin Integr 2020;20:0131. 